\title{
Fegindo
}

Revista Legado de Arquitectura y Diseño

ISSN: 2007-3615

ISSN: 2448-749X

legado_fad@yahoo.com.mx

Universidad Autónoma del Estado de México

México

\section{PROPUESTA METODOLÓGICA PARA EL ESTUDIO DE INTERSTICIOS URBANOS Y SU POTENCIAL USO COMO ESPACIO PÚBLICO}

Fernández-Gómez, Mónica Paola

PROPUESTA METODOLÓGICA PARA EL ESTUDIO DE INTERSTICIOS URBANOS Y SU POTENCIAL USO COMO ESPACIO PÚBLICO

Revista Legado de Arquitectura y Diseño, vol. 2019, núm. 26, 2019

Universidad Autónoma del Estado de México, México

Disponible en: http://www.redalyc.org/articulo.oa?id=477961406005

Esta obra está bajo una Licencia Creative Commons Atribución-NoComercial-SinDerivar 4.0 Internacional. 


\title{
PROPUESTA METODOLÓGICA \\ PARA EL ESTUDIO DE INTERSTICIOS URBANOS Y SU POTENCIAL USO COMO ESPACIO PÚBLICO
}

\author{
PROPOSED METHODOLOGY FOR THE STUDY OF \\ URBAN INTERSTICES AND THEIR POTENTIAL USE \\ AS PUBLIC SPACE
}

\author{
Mónica Paola Fernández-Gómez mpaola.fg@gmail.com \\ Universidad De La Salle Bajío, México
} Revista Legado de Arquitectura y Diseño,
vol. 2019, núm. 26, 2019

Universidad Autónoma del Estado de México, México

Recepción: 14 Febrero 2019 Aprobación: 30 Mayo 2019

Redalyc: http://www.redalyc.org/ articulo.oa?id $=477961406005$

\section{BY-NC-ND}

Resumen: La presente investigación analiza los procesos de expansión socio-espacial y territorial que generan una desconexión y desarticulación de la estructura urbana, que da origen a espacios intersticiales o vacíos urbanos.

Dichos espacios conllevan condiciones de segregación y marginación, por lo que este estudio resulta determinante para proponer alternativas de regeneración urbana que integren a la sociedad, en donde los nuevos modelos de planificación se definan bajo las premisas de intervención de sus principales vacíos urbanos determinando oportunidades y posibilidades que generen estrategias adecuadas a las realidades sociales.

Se estudia a partir de un enfoque morfológico los componentes de la estructura urbana como son: soporte estructural, físico, temporal y fenomenológico, para comprender las problemáticas que inciden en el deterioro del tejido urbano social y a su vez definir variables para tipificar los intersticios urbanos (como zonas abandonadas, vacíos geográficos e intersticiales), se analizan sus procesos de configuración y se describen sus características morfológicas, funcionales y socio-espaciales que favorecen en procesos de adaptación, ocupación y apropiación del espacio.

La importancia de esta investigación radica en desarrollar una metodología de caracterización para la elegibilidad de intersticios urbanos transformables a espacios públicos, con la finalidad de que estos sirvan como elementos articuladores de la estructura urbana existente, teniendo como caso de estudio una zona inserta en un polígono de desarrollo denominado por el IMPLAN (2015) como "Las Joyas" en la ciudad de León Guanajuato, México.

Palabras clave: espacio público, estructura urbana, vacío urbanos intersticiales.

Abstract: This research analyzes the process of socio-spatial and territorial expansion that generates a disconnection and dismantling of the urban structure, which gives rise to interstitial or empty spaces.

These spaces carry conditions of segregation and margination, so this study is determinant to propose alternatives of urban regeneration involving society, where new models of planning were defined under the premises of intervention of its empty main urban determining opportunities and possibilities that generate social strategies.

The urban structure as the structural, physical, temporal support stands and phenomenological, are analyzed from a morphological study to understand the problems that cause the deterioration of the urban-fabric and are defined different variables to establish the urban interstices (as areas abandoned, empty geographical, interstitial) analyzing the urban interstices configuration processes and describing their morphological, functional characteristics and socio-space. 
The importance of this research is to develop a methodology of characterization for the eligibility of transformable urban interstices in public spaces, taking as a case study an area of urban poverty called Las Joyas in Leon, Gto.

Keywords: public space, urban structure, empty urban.

\section{INTRODUCCIÓN}

Dada la disparidad en los criterios para abordar el tema de fragmentación urbana, las acciones emprendidas resultan aisladas y con impactos deficientes en los distintos sectores de la ciudad; por lo que esta investigación definirá variables para tipificar los intersticios urbanos y así contribuir al desarrollo de criterios de intervención más adecuados a la realidad y que incidan directamente en la mejora de las condiciones de habitabilidad urbana.

\section{Esta investigación defunirú variables

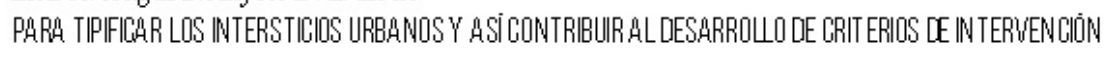 \\ más adecuados a la realidady que INCIDAN DIRECTAMENTE EN}

LA MEJORA DE LAS CONDICIONES de habitabilidad urbana.

La aportación de esta investigación radica en analizar los procesos de configuración de los intersticios urbanos, describir las condiciones morfológicas y socio-espaciales; lo que permitirá identificar indicadores que favorecen en los procesos de adaptación, ocupación y apropiación del espacio público para así emitir recomendaciones adecuadas para futuros proyectos de espacios públicos en espacios intersticiales, que promuevan modelos de articulación en la estructura urbana existente.

La zona de estudio seleccionada se encuentra inserta en un polígono de desarrollo definido por el implan (2012), “Las Joyas ”, en el cual es importante reconocer aquellos vacíos urbanos intersticiales con potencial de transformación a espacio público, que puedan contribuir a mejorar las condiciones de habitabilidad, partiendo de la estructuración del tejido físico y social.

Analizar las características morfológicas, funcionales y sociales de los vacíos urbanos en esta zona servirá para registrar y hacer evidentes las capacidades y cualidades que les confieren la capacidad de servir como elementos regeneradores e integradores socio-espaciales de los tejidos urbanos desarticulados y deteriorados en la zona. Se pretende desarrollar un método para la tipificación de vacíos urbanos ante la necesidad del aprovechamiento de aquellos espacios con potencial para la regeneración urbana en sectores marginados dentro de nuestra comunidad.

\section{ANTECEDENTES TEÓRICOS}

Con la finalidad de recabar conceptualizaciones teóricas sobre el objeto de estudio se revisan posturas de autores como Solà-Morales (2002), quien utiliza la expresión terrain vague, la cual tiene coincidencia con los vacíos urbanos, definidos como lugares sin una incorporación eficaz, aquellos espacios 
intraurbanos sin actividad, que permanecen fuera de la dinámica urbana.

Referente a clasificaciones tipológicas, Montalvo y Gutiérrez (2017) proponen una clasificación tipológica de vacíos en función a su relación con la estructura urbana, compuesta por: lotes baldíos, definidos como aquellos que tienen acceso a una calle pavimentada y con cobertura de servicios, ejemplificando con aquellos lotes inutilizados insertos en el tejido urbano; los corazones de manzana, insertos en la manzana, como jardines y patios, rodeados de construcciones; infraestructura de uso potencial, principalmente estacionamientos para distribución de cadenas de autoservicio; intersticios, aquellos huecos en la trama urbana, cuya escala es similar a la de una o varias manzanas urbanas, espacios sujetos a posible especulación; intervalos, terrenos que provocan una discontinuidad del tejido urbano, ubicados principalmente en la periferia de las ciudades y sin colindancia con zonas urbanas.

Francesco Careri (2013) hace referencia a los vacíos urbanos al mencionar que aunque el aspecto de estos en ocasiones es similar, su configuración es diversa, ya que son producto de distintos factores que dependen de las características de cada ciudad (Rojas, 2009).

Por su morfología, origen y características, los siguientes autores clasifican los vacíos de la siguiente manera:

a) Vacío fenomenológico, producto de las distintas variables a las que la ciudad presenta a lo largo de su historia (Careri, 2013) .

b) Vacío funcional, producto de los cambios y transformaciones en los ritmos y dinámicas urbanas (Chaline, 1981).

c) Vacío geográfico, producto de las características topográficas del sitio y de las transiciones o límites entre lo urbano y lo rural (Clichevsky, 2009).

\section{Vacío fenomenológico}

De acuerdo con Rojas (2009), desde el análisis de Lyotard y de Merleu-Ponty, se podría definir el vacío fenomenológico, como un lugar configurado a partir de hechos y acontecimientos producidos por el hombre o por agentes externos a la funcionalidad urbana de crecimiento y transformación, como son los desastres naturales y las guerras entre naciones. Este tipo de vacío se configura en sí mismo como un hecho autónomo de la ciudad, es decir, se construye a partir de su fenómeno, de su propio hecho. En esta categoría se podrían inscribir aquellos generados por las guerras, son terrenos que se presentan como piezas faltantes de la ciudad. Asimismo, las catástrofes naturales, como los sismos, incendios, inundaciones y erupciones volcánicas, se considerarían como hechos generadores de vacíos fenomenológicos. Los acontecimientos que configuran los vacíos fenomenológicos forman parte de la historia de la ciudad, por lo que la intervención en estos lugares requiere de un análisis desde el hecho que los originó y la relación espacial con el territorio que ocupan. 


\section{Vacío funcional/obsoleto}

El uso del espacio construido se va transformando, se generan alteraciones en las fuerzas que activan el funcionamiento de las ciudades, autores como Koolhas (2007), en su ensayo "Espacio Basura”, describe las problemáticas que se producen entorno al afán de edificar que ha permitido la generación de lugares "vacíos", con uso y utilidad, pero carentes de vida para la ciudad.

Para este caso de vacíos, el emplazamiento, la morfología y la relación con el lugar son fundamentales al momento de pensar en reintegrarlo al espacio urbano. $\mathrm{Al}$ ser producto del cambio, sea del sistema productivo, o por el cambio cualitativo de algún área, con el tiempo estos espacios quedan abandonados, como es el caso de infraestructuras en desuso.

\section{Vacío geográfico}

Los componentes que incluye el medio natural caracterizan al espacio físico que posibilita el soporte para la construcción y organización de los componentes de la estructura urbana de la ciudad. Todo territorio posee cierta pendiente que constituye un factor que condiciona los aspectos de urbanización, ya que la pendiente del terreno guarda una gran relación con la morfología de todas las formas del relieve; prácticamente todas ellas tienen un umbral límite que las clasifica o jerarquiza de acuerdo con su geometría; es decir, la pendiente favorece la delimitación de los procesos y los tipos de uso que se encuentran en el terreno (tabla 1) (Webber, 1982; Munizaga Vigil, 2000; Acuña Vigil, 2013).

Los elementos geográficos tienen la característica de generar discontinuidad en la morfología del tejido urbano, vacíos naturales que por su condición geográfica y ambiental conservan actualmente esta condición (ríos, colinas, pendientes, cañadas, entre otros).

La tabla 1 muestra la ponderación de pendientes y permite una evaluación de las mismas con fines de planeación o de regeneración urbana:

Tabla 1. Rangos de pendientes y sus posibilidades de uso urbano.

\begin{tabular}{|l|l|l|}
\hline $\begin{array}{l}\text { Rango de } \\
\text { pendiente } \\
\%\end{array}$ & $\begin{array}{l}\text { Posibilidades } \\
\text { de uso } \\
\text { urbano }\end{array}$ & Calificación \\
\hline $0-2$ & $\begin{array}{l}\text { Apto con } \\
\text { restricción }\end{array}$ & 3 \\
\hline $3-5$ & Apto & 5 \\
\hline $6-10$ & Apto & 4 \\
\hline $11-15$ & $\begin{array}{l}\text { Apto con } \\
\text { restricción }\end{array}$ & 3 \\
\hline $16-25$ & No Apto & 1 \\
\hline Más de 25 & No Apto & 0 \\
\hline
\end{tabular}

Fuente: IMPLAN (2012). 


\section{Vacios residuales/intersticial/latente}

Rodrigo Messen (2005) menciona que "los vacíos residuales los podemos entender como aquellas áreas en las cuales no se puede desplegar tipologías de intervención, son dependientes a una estructura mayor, es decir, no poseen ningún grado de autonomía que haga posible incidir o provocar un cambio sustancial sobre otra área. Estos espacios, como se mencionó, los encontramos de forma adyacentes a los no lugares". En el caso de la periferia marginal, son básicamente los bordes de las nuevas autopistas, que la cruzan, las cuales van sembrando de forma natural estos retazos.

A diferencia de los residuales, estos espacios, dentro de la política de Solà-Morales (2002) de terrain vague, son los posibles de re-significar y poner en valor, poseen una autonomía y una lógica propia, que permite desde ahí, establecer un nuevo orden sobre el contexto.

Sobre la periferia se mani fiestan de diversas maneras, pero esencialmente como aquellas áreas destinadas a equipamiento o áreas verdes que quedaron sin consolidar o sin ejecutar definitivamente, y que paradójicamente son las más agresivas.

\section{Intersticios urbanos}

El intersticio en el ámbito de la medicina, hace referencia al fluido intersticial que "es un reservorio y sistema de transporte de nutrientes y solutos que se distribuyen entre los órganos, células y capilares " (Bert, Pearce y R.H.,1984 ), su principal característica es que facilita los intercambios de nutrientes entre las diferentes células del cuerpo humano y que funciona como límite, en el cual, de acuerdo con las condiciones, cumple un rol específico provocando una dualidad, por lo tanto, su confi guración llega a ser ambigua.

El concepto de intersticio, "tradicionalmente entendido conlleva a una constante que se caracteriza por aquello que está "entre" dos partes. Ya sea un límite, un encuentro, una super ficie donde convergen dos medios diferentes o funciones al menos distintas" (Arze Arce, 2014).

Gustavo Munizaga (2002), define los espacios intersticiales como zonas heterogéneas de relleno o vacío, con una configuración débil de difícil defi nición, con condiciones de tipología edificatoria con poca consolidación morfológica y sin un orden aparente. Tummers (2006), los interpreta como aquellas zonas urbanas conectadas a las dinámicas de la ciudad, sin embargo, se mantienen aisladas dentro del tejido social y urbano, con posibles usos de ocupación que no tienen un reconocimiento formal, las actividades y estructuras se van configurando de manera emergente.

Por tanto, el intersticio es un elemento que puede originarse a partir de los fenómenos de expansión urbana, o de la yuxtaposición de distintas morfologías de tejido urbano (abierto y cerrado), éste puede llegar a ser un elemento generador de discontinuidades en el tejido urbano, pero en función de sus condiciones y capacidades morfológicas pude ser elegible para ser transformado a espacio público convirtiéndose así en un elemento 
integrador en la diversidad de configuraciones de tejidos urbanos y regenerador de aquellos que por la desconexión y desarticulación están deteriorados.

\section{MATERIALES Y MÉTODOS}

De acuerdo con Rojas (2009), los vacíos urbanos o intersticios son fragmentos insertos en la estructura urbana abandonados, territorios que quedaron en el olvido y que permanecen latentes para su uso, lugares que muestran ausencia de uso, pero también un sentido de libertad y de expectativa.

En general, el crecimiento expansivo que se presenta en la zona de estudio ha ido configurando zonas remanentes, carentes de planificación, espacios percibidos como zonas de abandono; son vacíos urbanos y sus categorías se definen a partir de distintos eventos y factores que los han generado.

Definición de Categorías: se estableció una catalogación de los intersticios acorde a su interacción con el tejido urbano (figura 1):

[VR]_Obras inacabadas. Vacíos residuales

[VL]_Solares vacantes. Vacíos latentes

[VO]_Infraestructuras públicas en desuso. Vacíos obsoletos

[VG]_Condiciones geográficas. Vacíos geográficos

[VI]_Discontinuidad Morfológica. Vacíos intersticiales

Definición de variables (figura 1):

- Configuración morfológica

Consiste en la identificación de elementos delimitantes que provocan las discontinuidades estructurales entre tejidos urbanos:

a) Borde (Delimitación física natural).

b) Limite (Delimitación física artificial).

c) Frontera (Delimitación virtual por uso y apropiación espacial).

- Características funcionales

Identificar su potencial de interacción mediante los aspectos de:

a) Conectividad (Elementos de unión y continuidad).

b) Accesibilidad (Capacidad de acceder física y visualmente).

c) Permeabilidad (Capacidad de interactuar en el espacio).

d) Relación espacial con los tejidos circundantes (Contexto).

- Características sociales

La percepción de la seguridad y la imagen urbana son factores complementarios del uso y apropiación de las formas urbanas en 
sus significados como imaginario colectivo de pertenencia y de identidad.

a) Seguridad.

b) Deterioro de la imagen urbana.

c) Esquemas de Apropiación.

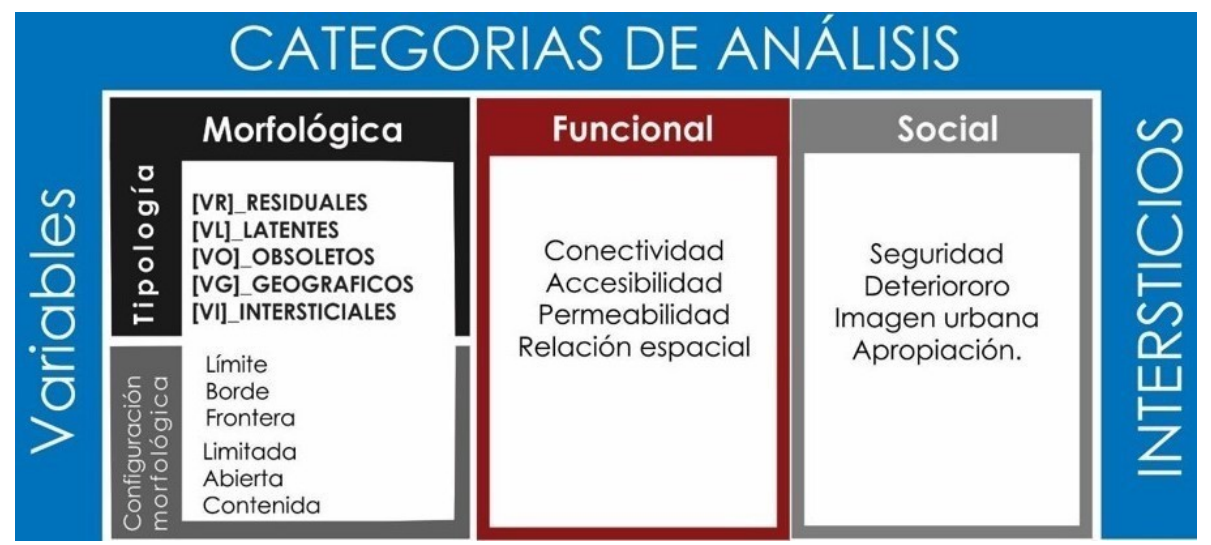

Figura 1. Categorías y variables de análisis para la valoración de la elegibilidad para su transformación. Fuente: Elaboración propia (2013).

\section{DEFINICIÓN DE LA ZONA DE ESTUDIO}

Referente a esta zona en el documento de Diagnóstico Municipal León 2015, elaborado por el IMPLAN, se determinaron "siete polígonos de pobreza urbanos, en los cuales se concentraban un gran número de personas con grandes carencias sociales. Dichos polígonos, en el 2015, se sometieron a una exhaustiva revisión de campo, con el objetivo de focalizar las zonas de la ciudad en donde se concentra la población con grandes carencias sociales, para dirigir la aplicación de los recursos municipales a las acciones, programas y proyectos de mayor impacto en el combate a la pobreza y al rezago social" (IMPLAN, 2015: 85). 


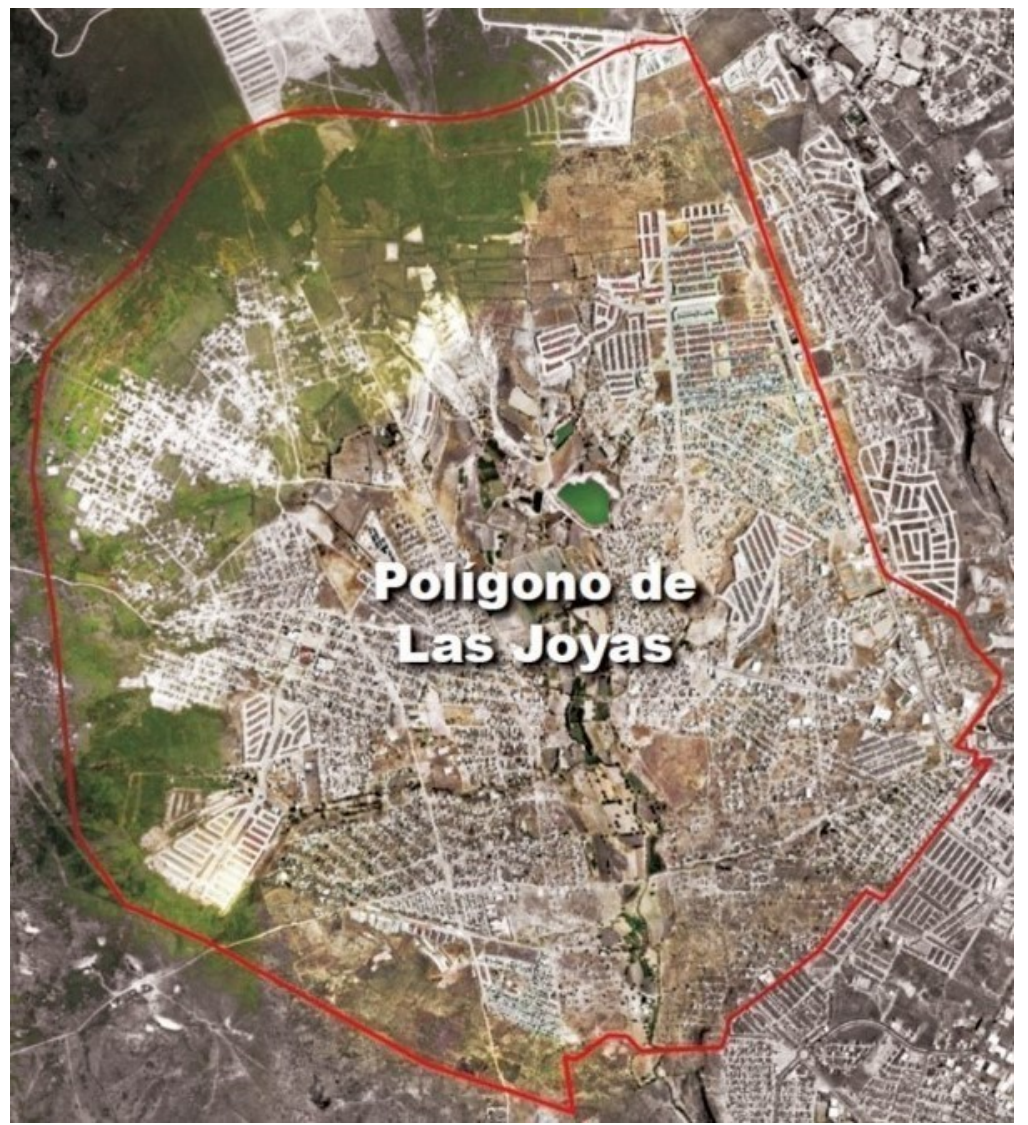

Figura 2. Polígono Las Joyas.

Fuente: IMPLAN (2012).

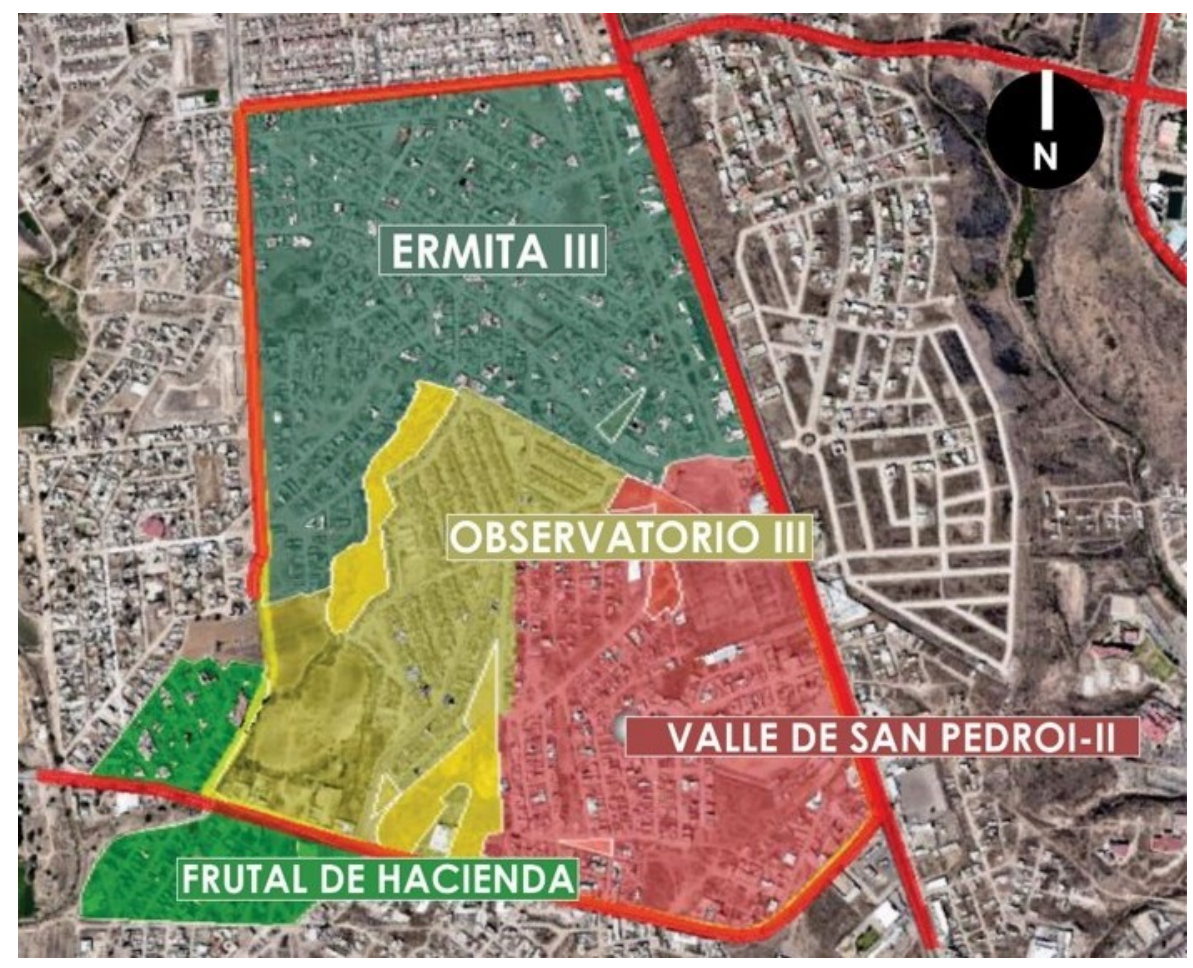

Figura 3. Zona de estudio y colonias que la conforman.

Fuente: Elaboración propia con base en Google earth (2014). 
La zona de estudio se encuentra localizada en la Zona Norponiente de la Ciudad de León Guanajuato y comprende las colonias (figura 3):

- La Ermita II.

- Observatorio III.

- Valle de San Pedro, sección Joya II.

En general, el tejido urbano de la ciudad de León Gto., se caracteriza por presentar una fragmentación que genera espacios residuales. A partir del análisis de las características y fenómenos urbanos mencionados, se identificó que en la zona de estudio el tejido urbano presenta fragmentación y segregación socio-espacial (figura 4) resultantes de las distintas condiciones y configuraciones de los fraccionamientos que se han establecido de forma regular como aquellos de carácter irregular, así como por la presencia de elementos urbanos como vialidades y acciones de ordenamiento territorial que hayan podido establecerse en diferentes momentos del crecimiento de la ciudad.
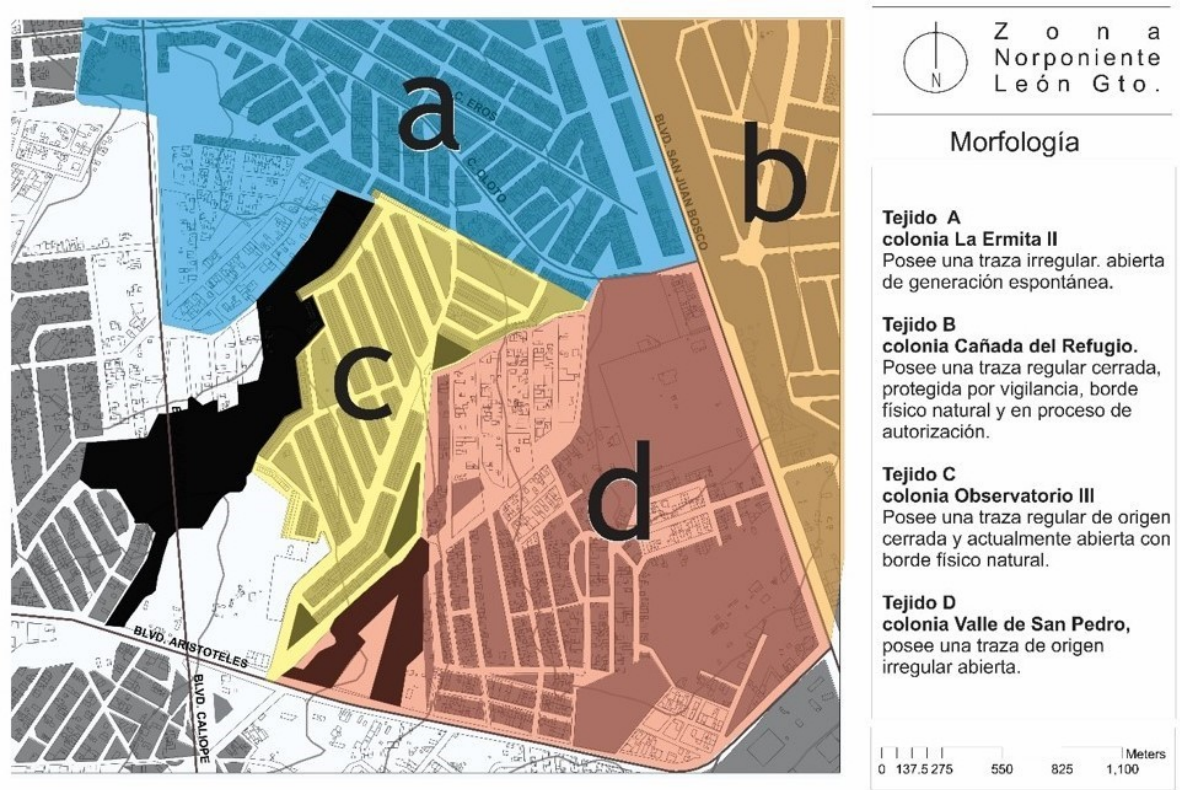

Figura 4. Morfología del tejido urbano de la zona. Fuente: Elaboración propia con base en INEGI (2010).

Los antecedentes de la zona de estudio sugieren que tuvo un crecimiento caracterizado por la presencia de desarrollos inmobiliarios cerrados y asentamientos periféricos que generaron una ausencia de interacción social en las comunidades de la zona.

Descripción y análisis de los intersticios urbanos en la zona de estudio:

En general, el crecimiento expansivo que se presentó en la zona de estudio configuró zonas remanentes, carentes de planificación, espacios percibidos como zonas de abandono; son vacíos urbanos y sus características se definen a partir de distintos eventos y factores que los han generado (figura 5). 


\section{IDENTIFICACIÓN DE VACÍOS EXISTENTES EN LA ZONA DE ESTUDIO}

Estos espacios tienen ciertas características para su definición:

- Los posibles usos en cuanto a ocupación no tienen un reconocimiento formal, sus actividades y estructuras se configuran de manera emergente.

- Su morfología es diversa, por lo tanto, sus dimensiones físicas carecen de escala fija.

- Son escenario para dinámicas negativas con relación a su entorno, favoreciendo aún más a su aislamiento.

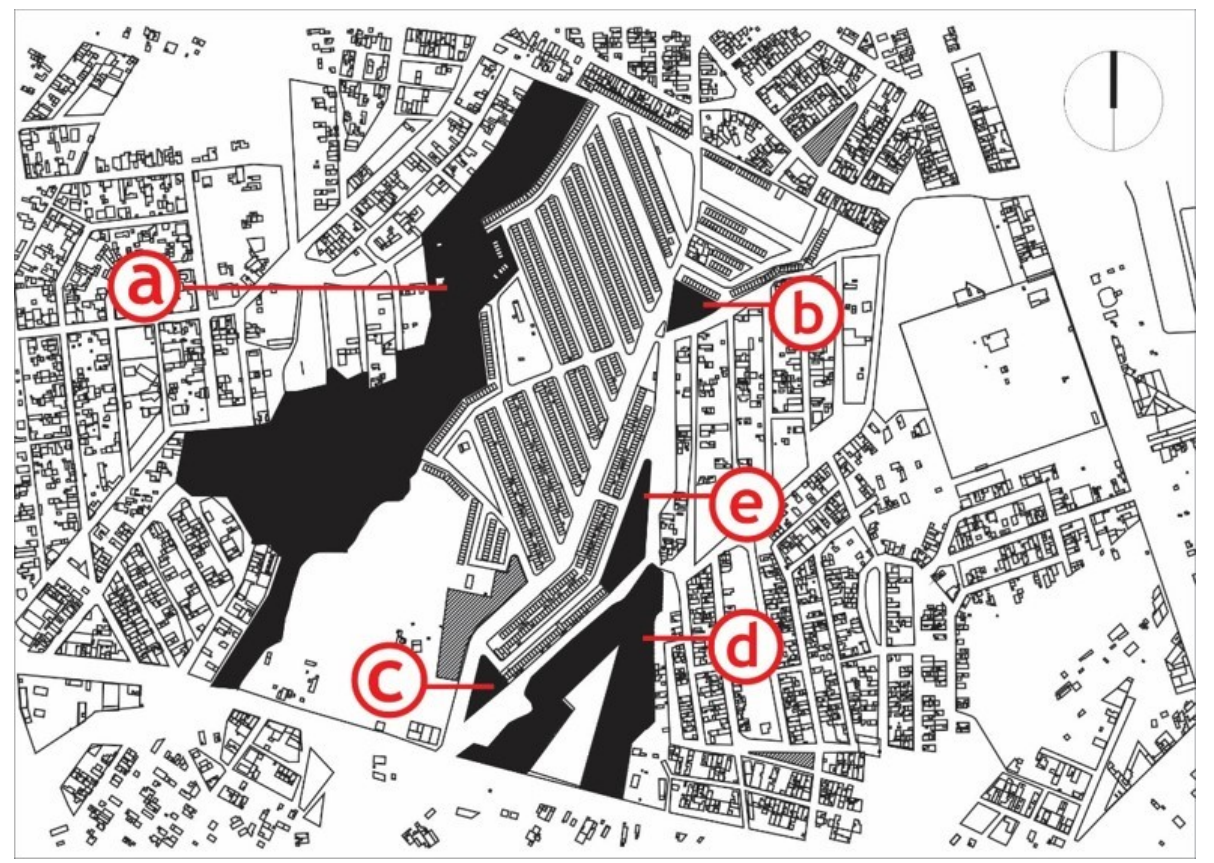

Figura 5. Vacíos e intersticios urbanos zona norponiente León Gto. Fuente: Elaboración propia (2013).

Clasificación de vacíos existentes en la zona de estudio.

[VR]_Obras inacabadas. Vacíos residuales.

[VL]_Solares vacantes. Vacíos latentes.

[VO]_Infraestructuras públicas en desuso. Vacío obsoleto.

[VG]_Condiciones geográficas. Vacíos geográficos.

[VI]_Discontinuidad Morfológica. Vacíos intersticiales. 


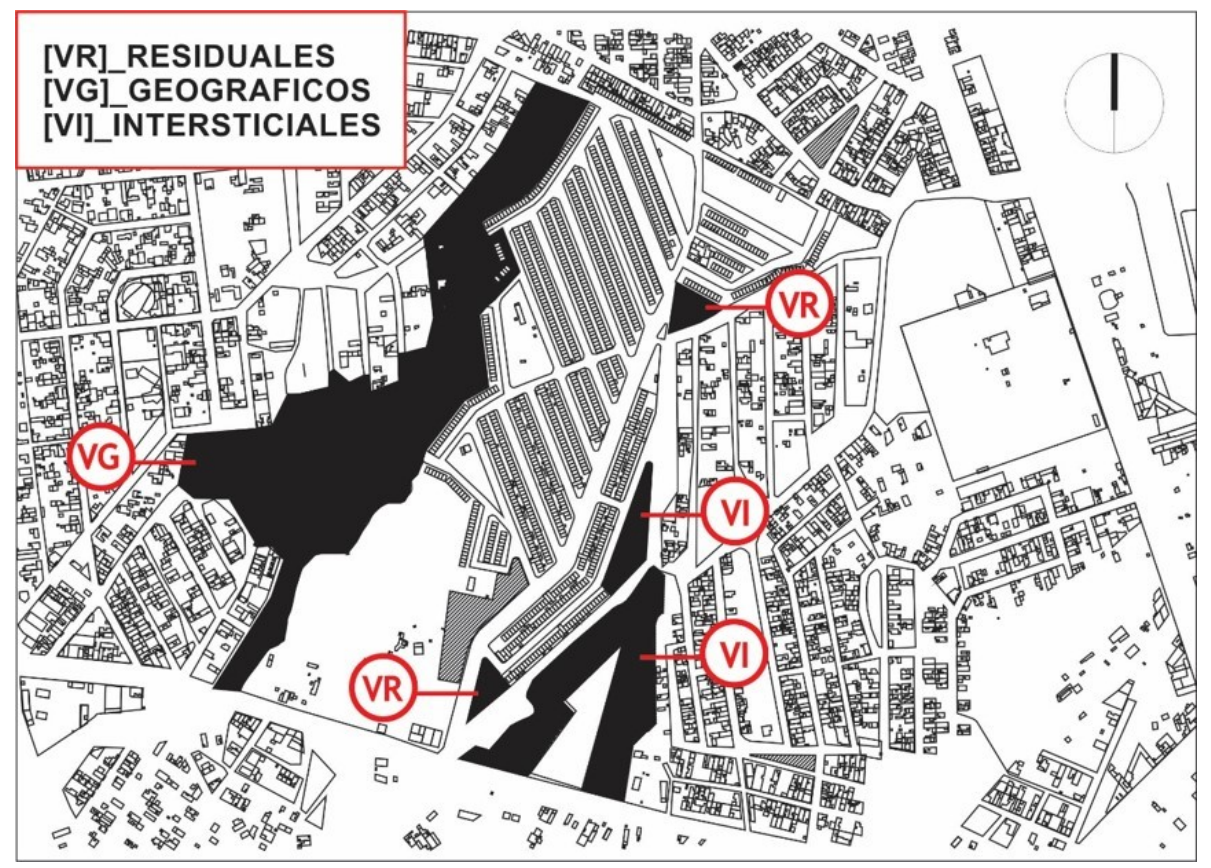

Figura 6. Clasificación de vacíos urbanos zona norponiente León Gto. Fuente: Elaboración propia (2013).

\section{ANÁLISIS Y Y CARACTERIZACIÓN DE INTERSTICIOS URBANOS}

A continuación se presenta un mapeo de la localización de los vacíos existentes en la zona, para realizar una clasificación para su estudio y caracterización como espacio público. 

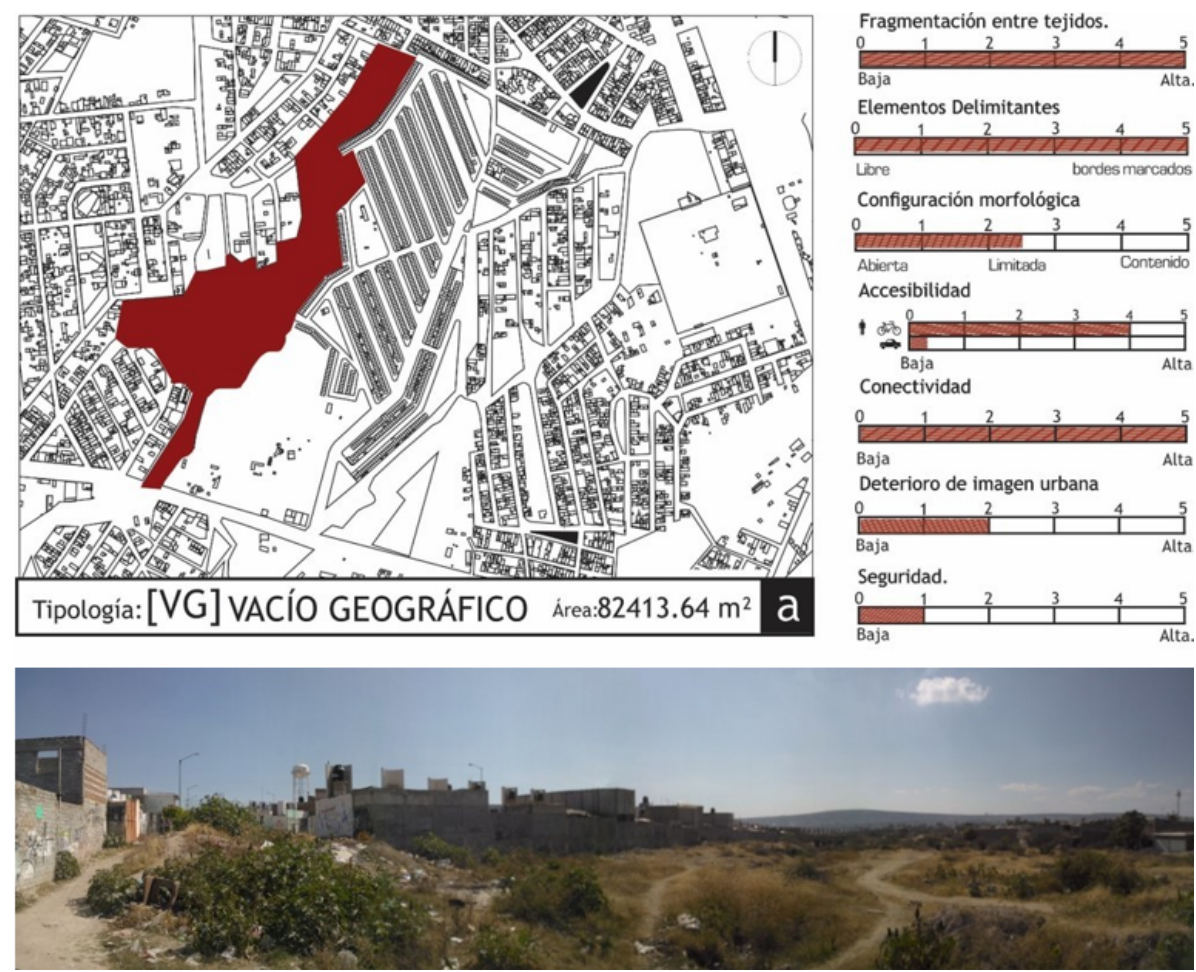

Figura 7. Intersticio urbano entre tejidos (Colonias Observatorio III y la Ermita II) León Gto. Fuente: Elaboración propia (2013) con base en INEGI (2010), e imagen tomada en sitio.
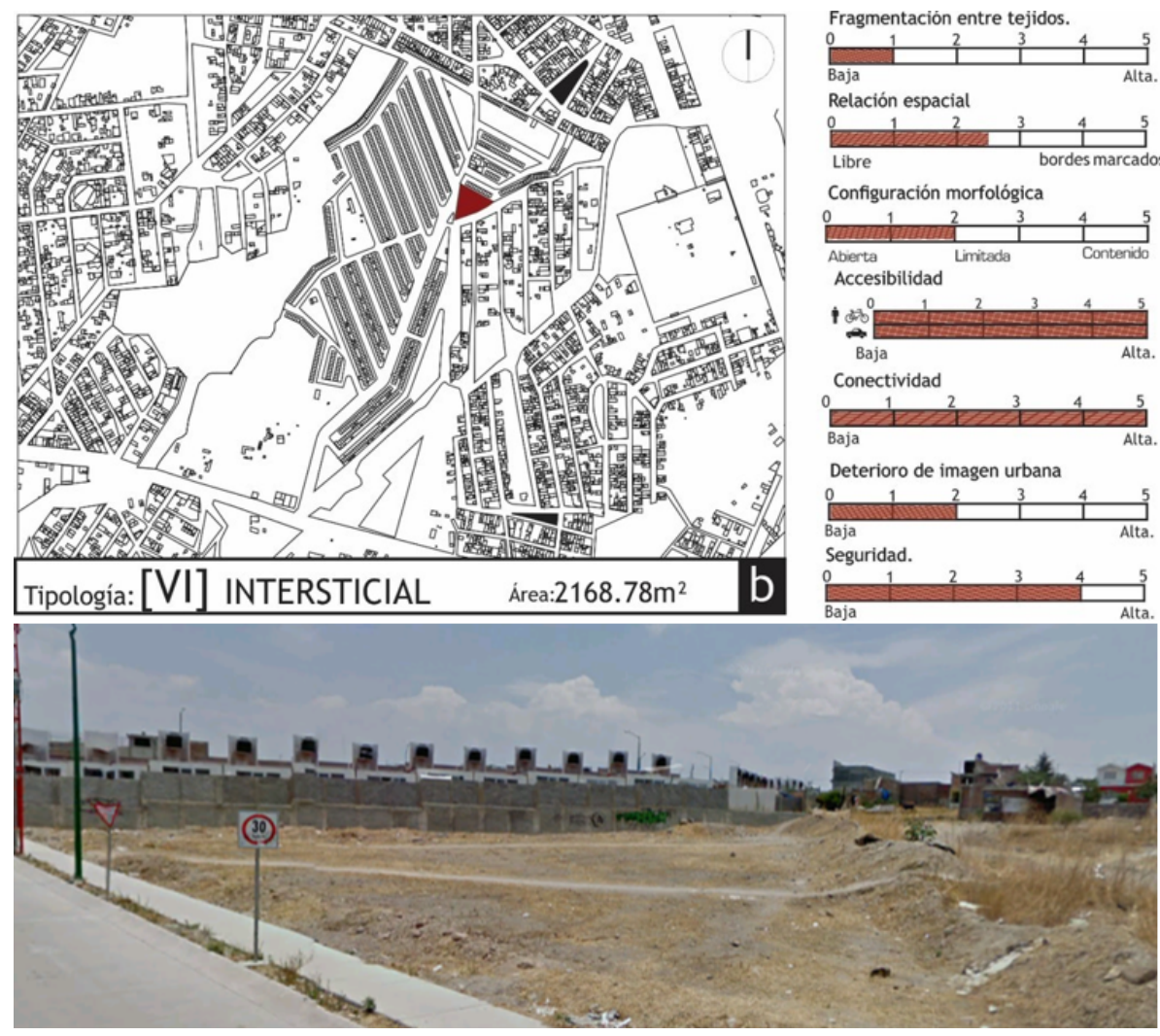

Figura 8. Intersticio urbano entre tejidos (Colonias Observatorio III y Valle de San Pedro) León Gto. Fuente: Elaboración propia (2013) con base en INEGI (2010), e imagen tomada en sitio. 

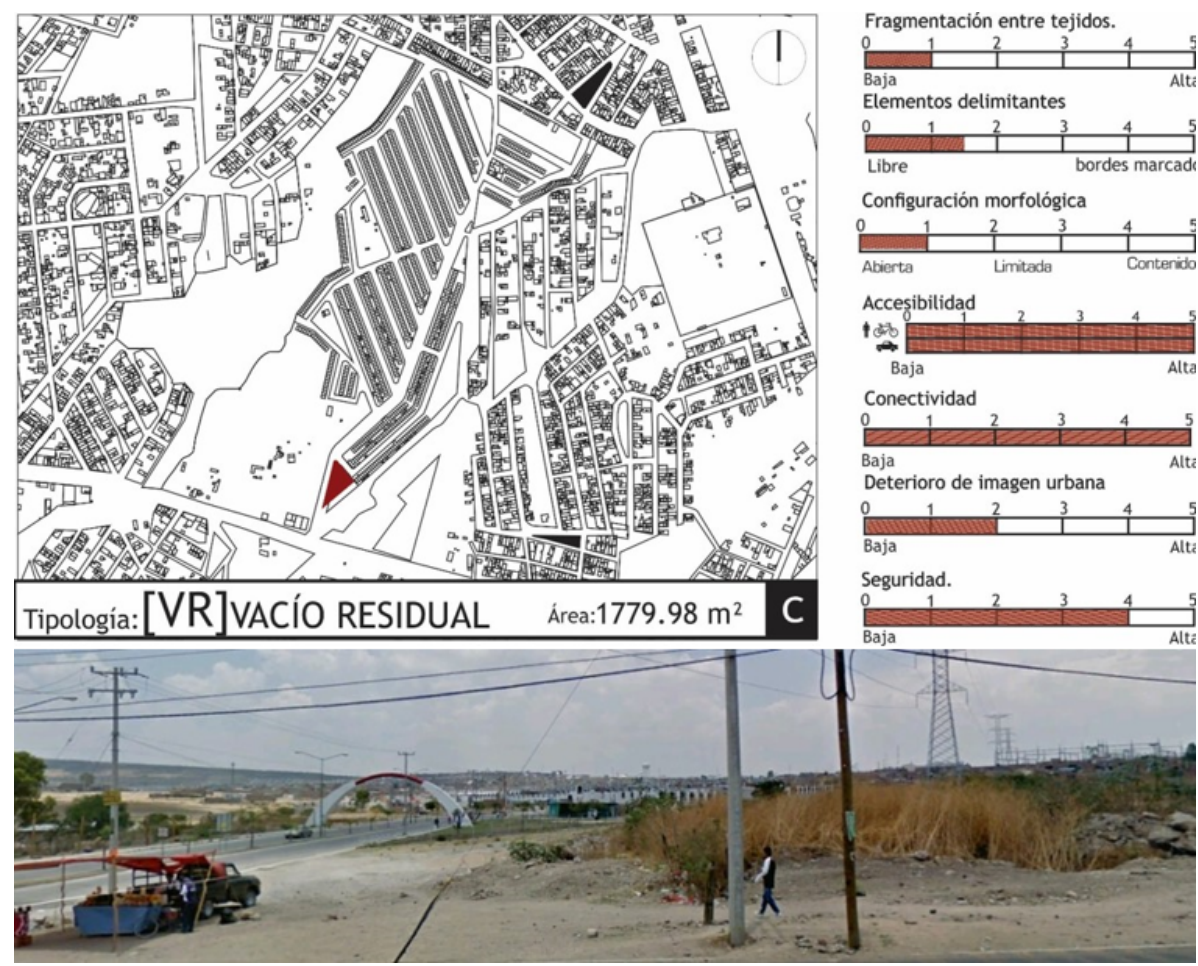

Figura 9. Intersticio urbano entre tejidos (Colonias Observatorio III y la Ermita II) León Gto. Fuente: Elaboración propia (2013) con base en INEGI (2010), e imagen tomada en sitio.
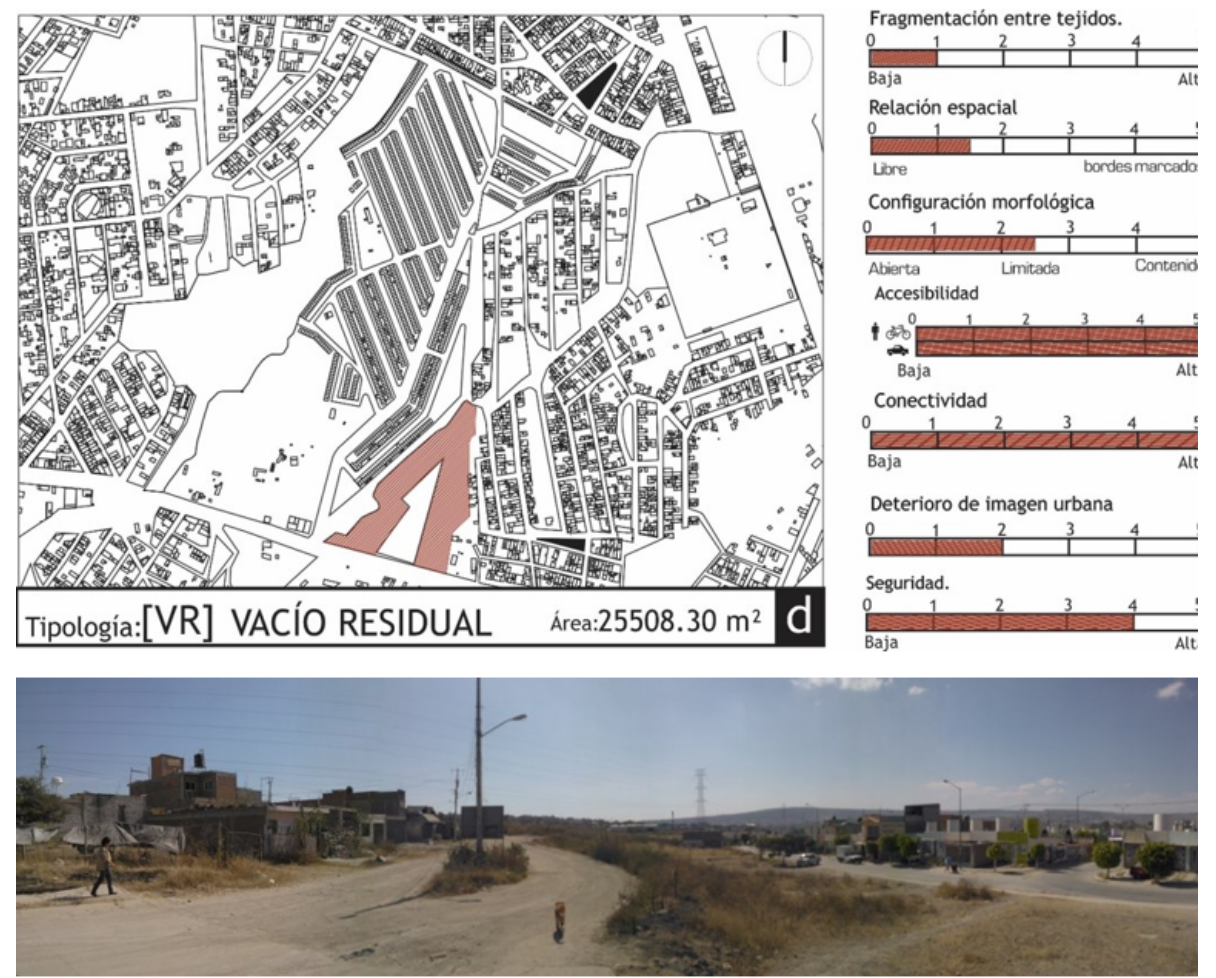

Figura 10. Intersticio urbano entre tejidos (Colonias Observatorio III y Valle de San Pedro) León Gto. Fuente: Elaboración propia (2013) con base en INEGI (2010), e imagen tomada en sitio. 


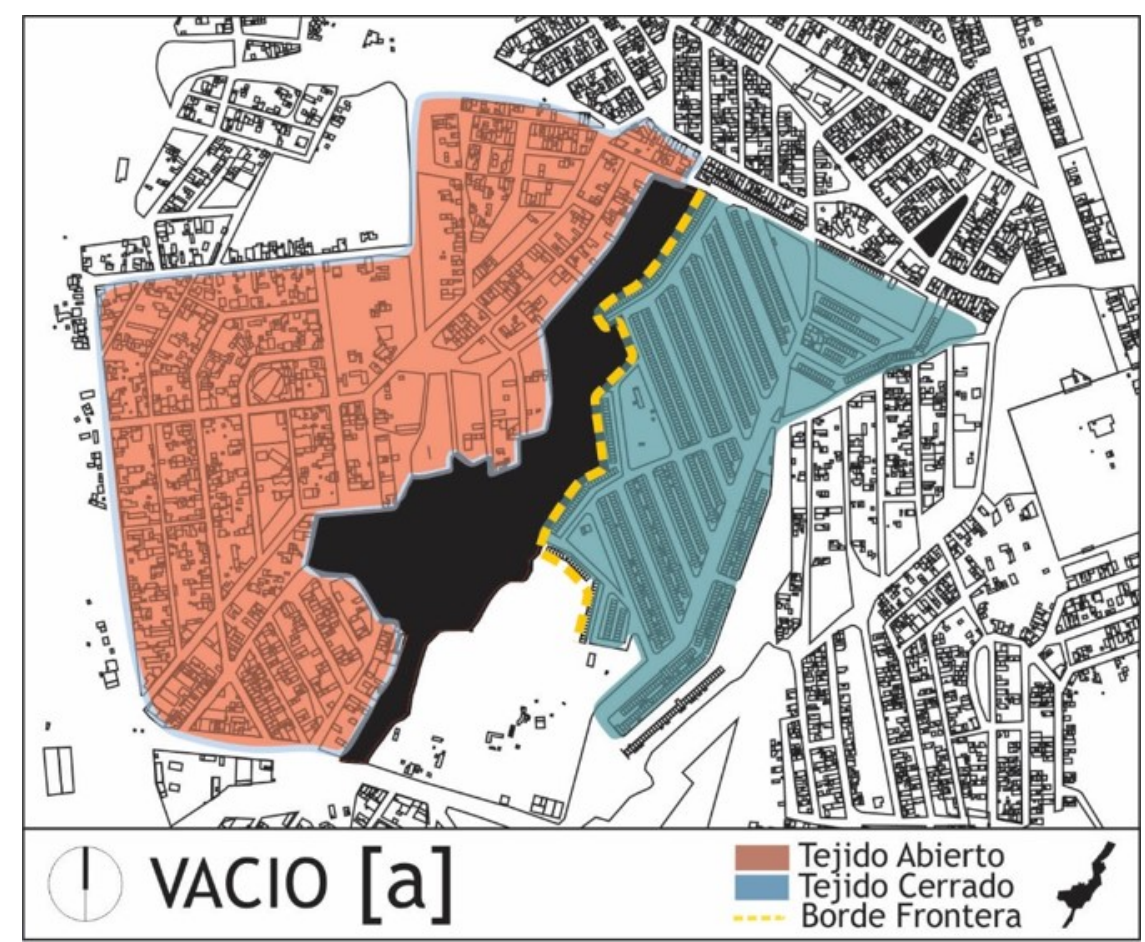

Figura 11. Intersticio urbano entre tejidos (Colonias Observatorio III y la Ermita II) León Gto. Fuente: Elaboración propia (2013) con base en INEGI (2010), e imagen tomada en sitio.

\section{RESULTADOS}

De acuerdo con el análisis realizado a los vacíos e intersticios de la zona de estudio, en función de las características detectadas, se hace la distinción de los casos representativos para su transformación como espacios públicos para conseguir una sutura o regeneración del tejido urbano.

\section{CASOS REPRESENTATIVOS}

Caso A: El Vacío[a] localizado en la zona de estudio se clasifica como Vacío Geográfico [VG] por sus condiciones topográficas, se caracteriza por generar una gran mancha de ruptura en la continuidad del tejido urbano y condicionar el desarrollo de su morfología (figura 12, 13 y 14).

Características: Presenta una gran movilidad peatonal, facilita la conexión entre la colonia de la Ermita y el Observatorio II hacia diferentes destinos, el uso de este vacío propicia la seguridad y apropiación del mismo. 


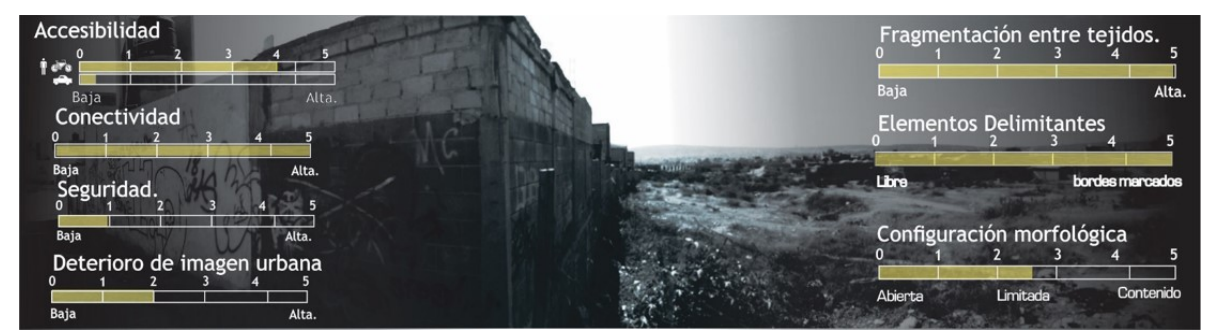

Figura 12. Análisis de vacío caso A.

Fuente: Elaboración propia (2013).

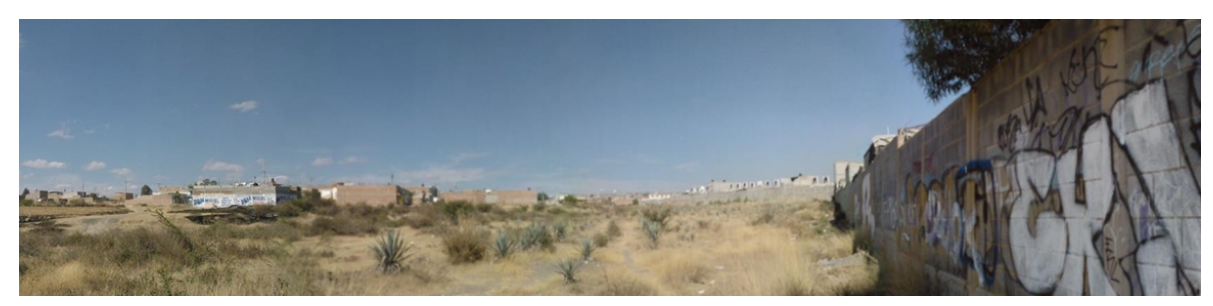

Figura 13. Análisis de variables caso A.

Fuente: Fotografía tomada en sitio (Observatorio III y la Ermita II) León Gto. (2013).

El desarrollo inmobiliario del Observatorio II en sus inicios fue planeado como fraccionamiento cerrado, sin embargo, por los fenómenos descritos en el sitio, éste se encuentra abierto y es permeable. Su morfología condiciona las situaciones que suceden en él y determina que se necesitan espacios que interconecten las funciones con los tejidos adyacentes.

Este vacío geográfico (figura 14), por sus condiciones topográficas propicia desintegración socio-espacial, y presenta límites y bordes marcados por la discontinuidad morfológica entre los tejidos adyacentes. 


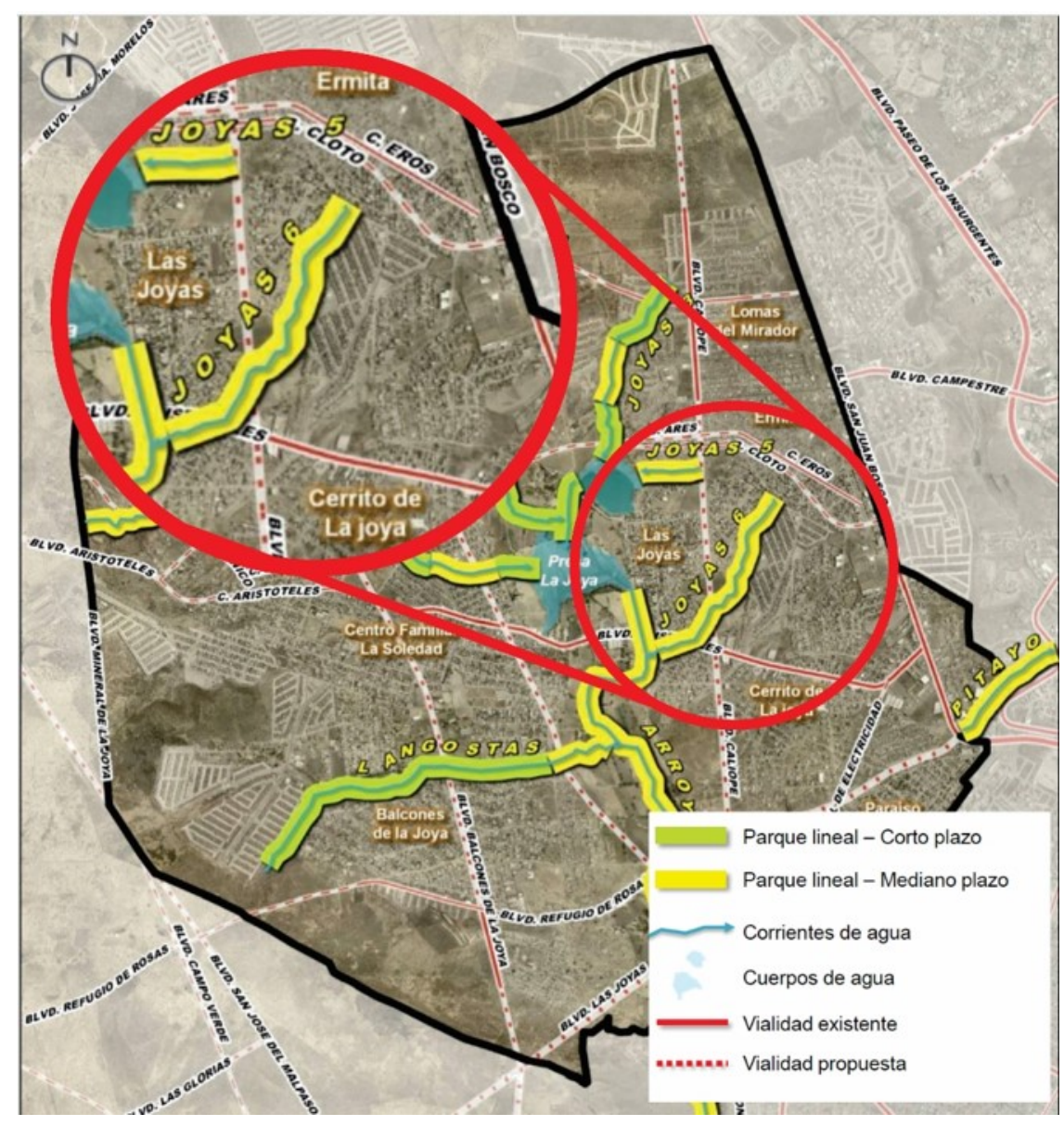

Figura 14. Vacío caso A.

Fuente: Fotografía tomada en sitio (Observatorio III y la Ermita II) León Gto. (2013).

Los resultados de las categorías de análisis permiten diagnosticar que el potencial de oportunidad de este vacío es alto y su grado de impacto es negativo alto, es altamente perjudicial para el paisaje urbano, por lo que su reactivación o transformación es imprescindible. Al ser transformado reacondicionándolo como espacio público podría funcionar como un elemento de sutura del tejido al lograr integrar y regenerar bordes (figura $12,13$ y 14$)$.

El resultado del análisis de este vacío intersticial sirve como comprobación de la efectividad de la metodología, ya que se ve reflejado (figura 15) en que en los estudios realizados por IMPLAN (2012) recientemente en el polígono de Las Joyas en el cual contemplan un parque lineal en este vacío. 


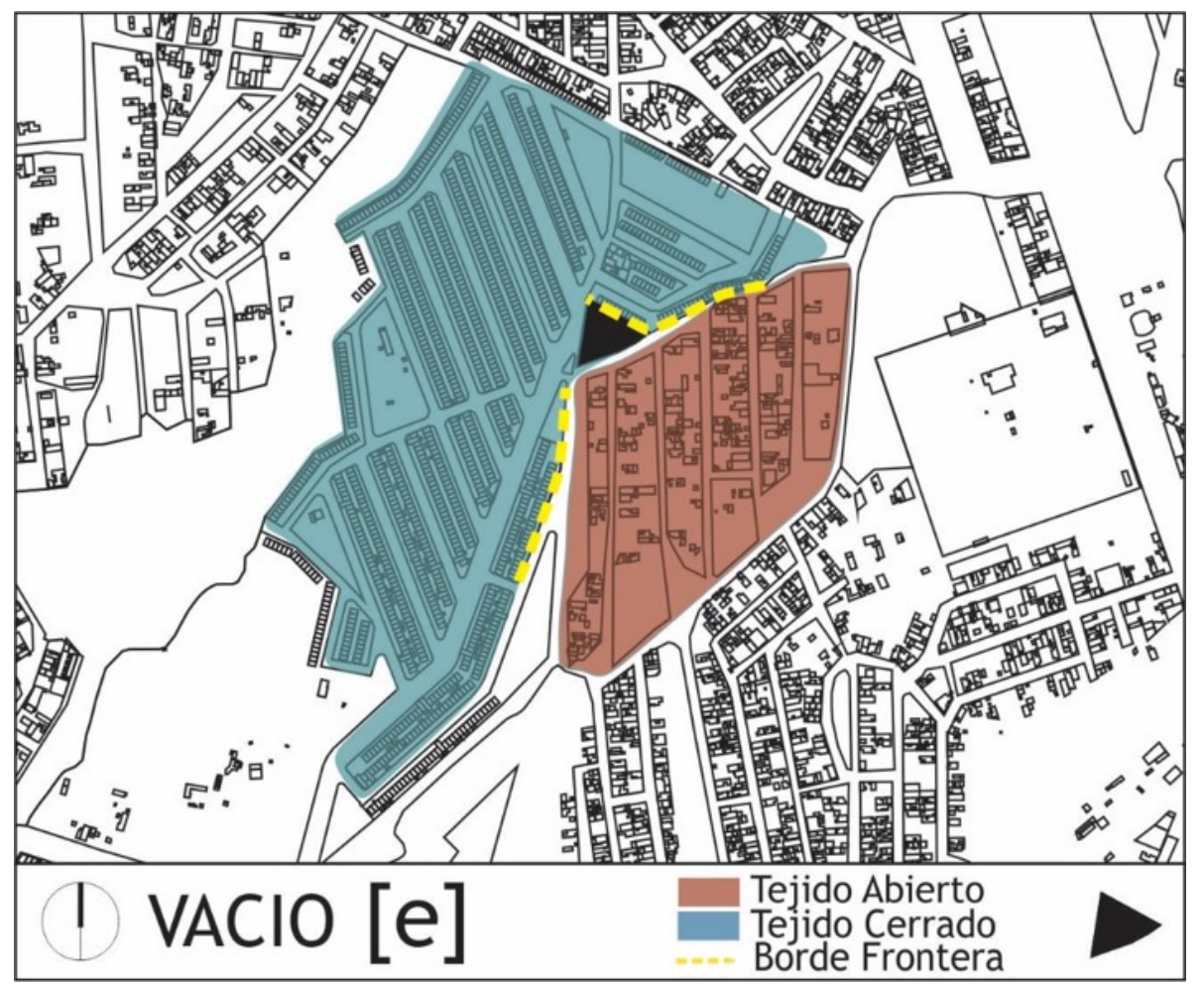

Figura 15. Propuesta de parques lineales en el polígono Las Joyas, León Gto. Fuente: IMPLAN (2012).

Caso E: El Vacío urbano[e] se clasifica como Intersticial [VI] surge de una discontinuidad morfológica, provocada por la yuxtaposición de tejidos urbanos de distintas morfologías inconexos generando bordes; estas morfologías se encuentran condicionadas por la topografía del sitio (figura 16, 17 y 18).

Características: El tránsito peatonal que existe dentro de él es alto, propiciado por la conexión entre las colonias Observatorio III y Valle de San Pedro I para satisfacer el tránsito de los habitantes y caminantes. Su baja apropiación propicia la inseguridad e induce un deterioro de imagen urbana.

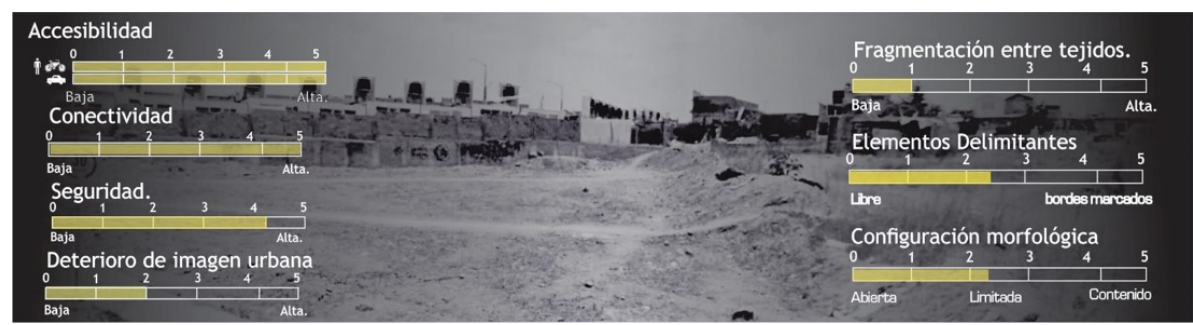

Figura 16. Análisis de vacío caso E.

Fuente: Elaboración propia (2013). 


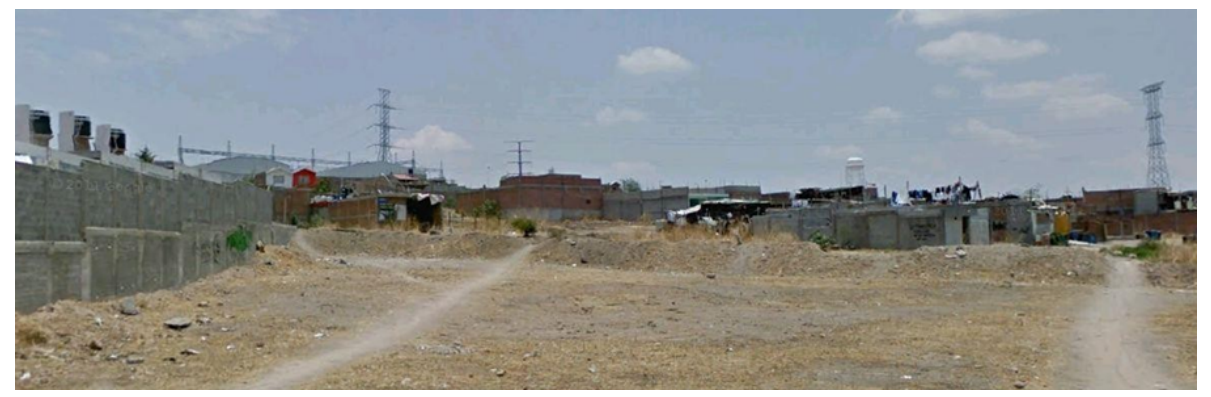

Figura 17. Análisis de variables caso E.

Fuente: Fotografía tomada en sitio (Observatorio III y la Ermita II) León Gto. (2013).

Los resultados de las categorías de análisis nos permiten diagnosticar que el potencial de oportunidad de este vacío de tipo intersticial es alto y su grado de impacto es negativo medio, la existencia de ese vacío en las condiciones actuales es desfavorable, pero con alto potencial para reactivarse.

Su transformación es importante para mejorar la calidad de vida de los habitantes de dichas colonias y a su vez generar una integración entre tejidos y regeneración de bordes, que propicie la seguridad y apropiación del mismo.

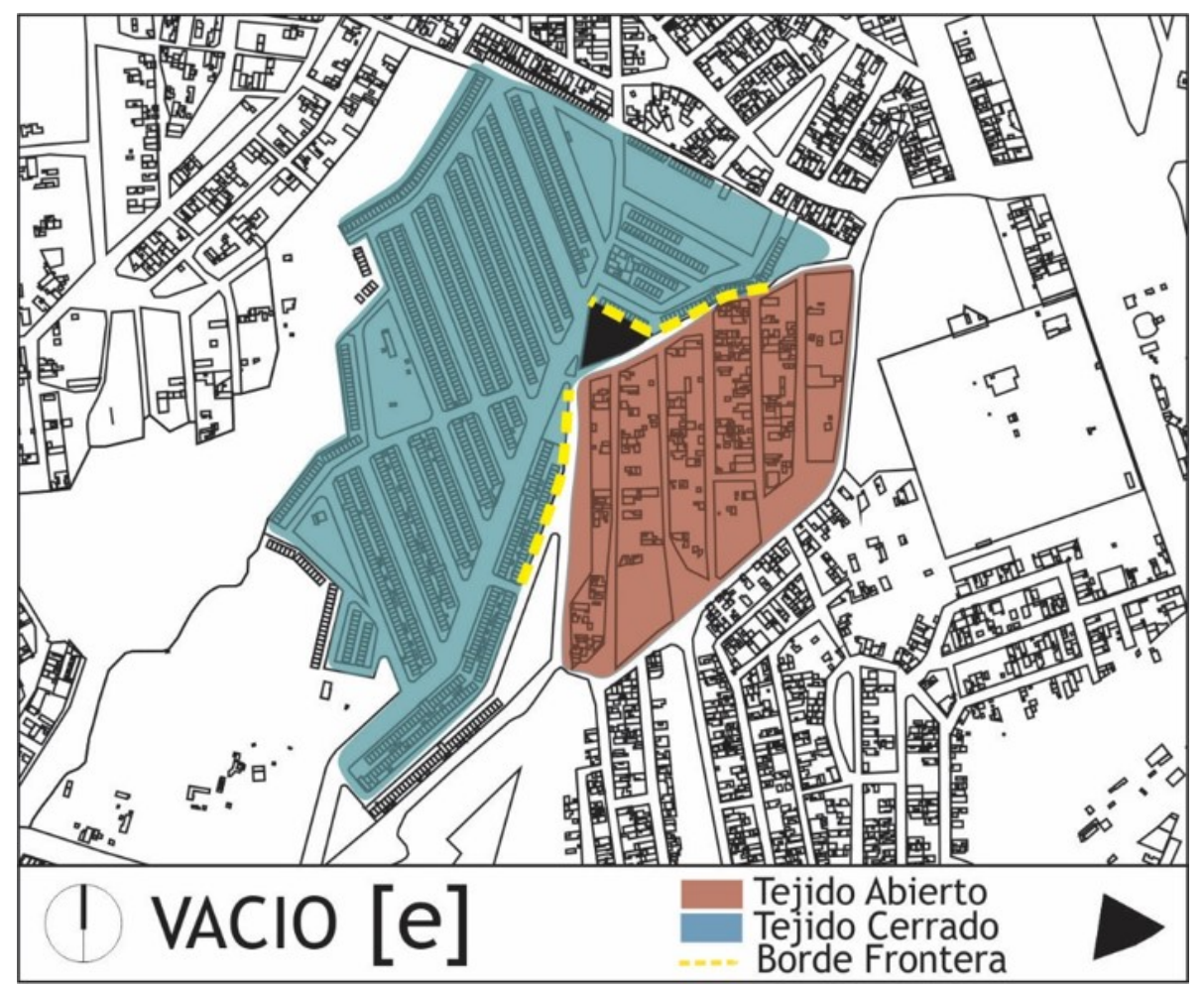

Figura 18. Vacío caso E.

Fuente: Fotografía tomada en sitio (Observatorio III y la Ermita II) León Gto. (2013).

La zona de estudio presenta una desarticulación del tejido urbano, paisajes naturales degradados y vacíos o intersticios, estos aportan oportunidades de desarrollo como elementos de sutura y regeneración entre tejidos de la ciudad. Los criterios para la caracterización de estos intersticios como espacios públicos, en principio están íntimamente 
ligados a la presencia y relevancia de los componentes edificados y naturales que los contienen.

$\mathrm{Al}$ proponer la transformación de estos a través de la caracterización a espacio público se busca su incorporación funcional como un soporte intermedio entre las distintas morfologías del tejido de la zona.

Con base en lo percibido en las encuestas y la observación cartográfica se verifica que los Intersticios al ser espacios en movimiento y conflicto constantes, y de uso esporádico, pudieran ser transformarlos en espacios públicos considerándolos como zonas de gran potencial para canalizar los requerimientos de una situación socio-cultural fragmentada generada ante la carencia de espacios dignos para la convivencia.

Estos espacios no son planificados por quienes desarrollaron el crecimiento de la zona, haciendo que los habitantes se apropien de los intersticios transformados en espacios públicos.

La caracterización del intersticio como espacio público toma las propiedades conectivas de la morfología de estos y las propiedades de cohesión social del espacio público para lograr una sutura o regeneración del tejido adyacente a los intersticios.

El espacio público es uno de los principales elementos que interfieren en la construcción de la vida urbana, por su complejidad es multidimensional, razón por la cual se puede estudiar desde diferentes enfoques o disciplinas para analizar sus conformaciones y transformaciones físicas, su significado social, político y cultural, que son características que van estructurando y conformando el territorio (Fernández, 2017).

De acuerdo con el análisis realizado de los casos representativos y a partir de una revisión sobre los aportes teóricos de autores como: Manuel Delgado, Jordi Borja, David Harvey, Jan Gehl, entre otros, sobre el espacio público se definieron características funcionales para cada elemento que al ser coincidentes le transfieren a los vacíos intersticiales potencial de transformación a espacio público (figura 19).

\section{DISCUSIÓN}

A partir del estudio realizado se puede inferir que la morfología de la ciudad es el resultado de procesos metabólicos que a través del tiempo se expresan en mutaciones derivadas de incrementos en la densidad de población, cambios o transformaciones en usos de suelo y flujos viales que van modificando y transformando su trama.

\section{Lacomprens ión de los vacíos urbaras intersticiuzles más \\ COHO RESULIADO DE DICHOS PROCESOS OUE CONO CONDICIONFIISICA DE LACIUDAD, \\ PERMITE RECONOCER SU POTENCIAL COMO ELEMENTO CLAVE \\ para el desarrollo de la cudad de manera artic ulada y continua.}

La comprensión de los vacíos urbanos intersticiales más como resultado de dichos procesos que como condición física de la ciudad, permite 
reconocer su potencial como elemento clave para el desarrollo de la ciudad de manera articulada y continua.

Es importante reconocer que para el análisis de los vacíos intersticiales o intersticios urbanos, el límite de lo construido es fundamental, tanto en la definición de su emplazamiento como en ciertas configuraciones del tejido urbano. Los intersticios urbanos por su capacidad de articular conexiones entre las diversas configuraciones de los tejidos urbanos que conforman la ciudad, pueden llegar a ser una alternativa de sutura, por sus características y condiciones morfológicas que pueden llegar a ser potencialmente susceptibles a atender nuevas demandas sobre el uso del espacio, tal es el caso de los desplazamientos peatonales, en los cuales la percepción del vacío es un factor imprescindible al momento de plantear alternativas de ocupación, al ser transformado como espacio público. Para Borja y Muxí (2003), el espacio público supone, pues, dominio público, uso social colectivo y multifuncionalidad y que su calidad se podrá evaluar en función de la intensidad y la calidad de las relaciones sociales que este facilite, por la intensidad mixturante de grupos y sus comportamientos, así como por su capacidad de estimular la identificación simbólica, la expresión y la integración culturales.

De acuerdo con Asher (2004), el neourbanismo intenta resolver los problemas caso por caso y elaborar soluciones adaptadas a cada situación. La experiencia, el conocimiento y la técnica no se utilizan para aplicar soluciones repetitivas, sino para aumentar sus posibilidades de adaptación a contextos particulares, cambiantes e inciertos. Los nuevos modelos de planificación deben definirse con las premisas de intervención de sus principales vacíos urbanos, determinando sus oportunidades y posibilidades, generando así estrategias de intervención sintonizadas con las realidades locales.

Las estrategias de gestión y de diseño urbano que se han realizado hasta ahora sobre la necesidad de rehabilitar vacíos urbanos como alternativa de sutura en tejidos desarticulados y desconectados, permiten abordar la idea sobre el desarrollo de una propuesta para caracterizarlos y valorarlos, mediante las categorías y variables propuestas, con la finalidad de reconocer cualidades que en los espacios públicos favorecen los procesos de adaptación, ocupación y apropiación, transfiriéndole así la capacidad de ser elegibles para su transformación. "No se trata de la cantidad de gente, sino de la sensación de que ese lugar está poblado y de que la gente lo usa" (Gehl, 2014).

\section{CONCLUSIONES}

Esta propuesta podría contribuir a que en los procesos de diseño urbano se disminuyan acciones que propicien la discontinuidad de los tejidos ya consolidados en otras zonas. Es importante mencionar que para la transformación e intervención de intersticios se requiere la revisión de los planes y programas de desarrollo urbano ofrecidos por las sucesivas administraciones municipales y la participación de diseñadores urbanos y de paisajismo, para generar propuestas que promuevan la humanización y 
urbanización de estos vacíos o intersticios, como espacios públicos, cuyo diseño y proyección brinden andadores que propicien la movilidad. Según Gehl (2014), los trayectos directos, lógicos y compactos, las dimensiones espaciales a una escala amigable, sumadas a una clara jerarquía del valor de los espacios, son factores que inciden en alentar la creación de vida urbana al generar nuevos recorridos y puntos de enlace entre tejidos de condiciones morfológicas distintas.

\section{Agradecimientos}

A la Universidad De La Salle Bajío por su apoyo y reconocimiento al presente trabajo en el 6to Concurso de Investigación para Alumnos y Egresados de Licenciatura. A mi familia, por su apoyo incondicional y a los Doctores Alejandro Guzmán Ramírez y Mariano Ferretti Ramos, por su gran disposición para sumar conocimiento y su continua aportación a la discusión urbana actual.

\section{FUENTES DE CONSULTA}

Acuña Vigil, P. (2013), Estructura urbana "Resultados de la búsqueda POLIS-CIVITAS”. [En línea] https://pavsargonauta.wordpress.com/? $s=$ estructura+urbana\&submit=, consultado el 19 de mayo de 2019 .

Arze Arce, G. (2014), "El Intersticio como nuevo soporte del diseño urbano de la sociedad contemporánea”. Revista de Urbanismo, vol. 16, núm. 31, pp. 4-6. doi: 10.5354/0717-5051.2014.30993.

Asher, F. (2004), Los nuevos principios del urbanismo. El fin de las ciudades no está a la orden del día, Editorial Alianza, Madrid.

Bert, J. L., Pearce, R. H. (1984), “The interstitium and microvascular exchange”. In Handbook of Physiology (en inglés), vol. IV. American Physiological Society, Bethesda, MD. ISBN 0683072021 . OCLC 4775901.

Borja, J., Muxí, Z. (2003), El espacio público, Electa, Barcelona.

Careri, F. (2013), Walkscape, El andar como práctica estética. 2a ed., Editorial GG, España.

Clichevsky, N. (2009), "Algunas reflexiones sobre informalidad y regularización del suelo urbano". Revista Bitácora Urbano Territorial, vol. 1, núm. 14, pp. 63-88. ISSN: 0124-7913. [En línea] https://www.redalyc.org/ articulo.oa?id=748/74811914005, consultado el 20 de mayo de 2019.

Chalin, C. (1981), La Dinámica Urbana, Colección Nuevo Urbanismo, Madrid.

De Solá Morales, I. (2002), Territorios, Editorial Gustavo Gili, Barcelona.

Fernández Gómez, M. P. (2017), "El orden de lo emergente. Metodología para la caracterización de los espacios públicos en contextos emergentes. Caso de estudio: Zona Norte de la Cd. de León, Guanajuato.” (Tesis de Maestría). Universidad De La Salle Bajío, León, Guanajuato.

Gehl, J. (2014), Ciudades para la gente, Infinito, Buenos Aires.

Instituto Municipal de Planeación (IMPLAN) (2012), Polígono de las Joyas, [ En línea ] https ://www .implan .gob.mx/publicaciones /poligonos - dedesarrollo.html, consultado el 13 de septiembre de 2013. 
Instituto Municipal de Planeación (IMPLAN) (2015), Diagnóstico del Municipio de León.

Instituto Nacional de Estadística y Geografía (INEGI) (2010), Censos de Población y vivienda 2010, s.l.: s.n.

Koolhaas, R. (2007), Espacio Basura, Editorial Gustavo Gili, Barcelona.

Messen Montecinos, R. (2005), Exploración y puesta en valor de "Vacíos" urbanos, como estrategia de desarrollo para barrios periféricos marginales de Santiago. [En línea] http://fidonline.ucentral.cl/trabajos_estud_seminarios/ seminarios05_modulo_10/rodrigo_messen.pdf, consultado el 20 de enero de 2013.

Montalvo Vargas, R. y Gutiérrez Carreón, Mayela M. (2017), "Vacíos urbanos para vivienda en la ciudad de Puebla, México", Vivienda y Comunidades Sustentables, año 1, núm. 2, Universidad de Guadalajara, Laboratorio Nacional de Vivienda y Comunidades Sustentables-CONACYT, México.

Munizaga Vigil, G. (2000), Macroarquitectura, tipologías y estrategias de desarrollo urbano, Alfaomega, México.

Rojas, A. (2009), Ciudad Viva. [En línea] http://www.laciudadviva.org/blogs/? $\mathrm{p}=2973$, consultado el 26 de febrero de 2013

Tummers, L. (2006), citado en Giuseppe Dematteis. En la encrucijada de la territorialidad urbana. Revista Bitácora Urbano Territorial, vol. 1, núm. 10, pp. 53-63.

Webber, M. (1982), Indagaciones sobre la estructura urbana (2nd ed.), G. Gili, Barcelona. 
